\title{
A Compact Planar UWB Antenna with Triple Controllable Band-Notched Characteristics
}

\author{
Chaabane Abdelhalim ${ }^{1}$ and Djahli Farid ${ }^{2}$ \\ ${ }^{1}$ Laboratoire des Télécommunications, Faculté des Sciences et de la Technologie, Université 8 mai 1945 Guelma, \\ 24000 Guelma, Algeria \\ ${ }^{2}$ Laboratoire LIS, Faculté de Technologie, Université Ferhat Abbas Sétif, 19000 Sétif, Algeria
}

Correspondence should be addressed to Chaabane Abdelhalim; chaabaneabdelhalim@yahoo.fr

Received 27 May 2013; Revised 14 December 2013; Accepted 22 December 2013; Published 6 February 2014

Academic Editor: Rashed Mohassel

Copyright (c) 2014 C. Abdelhalim and D. Farid. This is an open access article distributed under the Creative Commons Attribution License, which permits unrestricted use, distribution, and reproduction in any medium, provided the original work is properly cited.

A modified compact planar ultrawideband (UWB) monopole antenna with triple controllable band-notched characteristics is presented in this paper. The proposed antenna consists of a modified stair cased V-shaped radiating element and partial ground plane. The triple band-notched characteristics are achieved by embedding two different vertical up C-shaped slots with a vertical down C-shaped slot in the radiating patch and in the ground plane, respectively. Besides, the bandwidth of each rejected band can be independently controlled by adjusting the dimensions of the corresponding band notched structure. The proposed antenna with rejected bands characteristics is successfully simulated, prototyped, and measured. The measured results show that the antenna operates until upper $11 \mathrm{GHz}$ for voltage standing wave ratio (VSWR) is less than 2, and exhibits bands rejection of $1.6-2.66 \mathrm{GHz}$ (49.76\%), 3-4 GHz (28.57\%), and 5.13-6.03 GHz (16.12\%). Moreover, the proposed antenna shows a near omnidirectional radiation patterns, stable peak gain, and with small group delay and transfer function variation on the whole UWB frequency range except in the notched frequency bands, which makes it suitable for being used in the future UWB applications.

\section{Introduction}

Ultrawideband (UWB) is specified in the Federal Communication Commission (FCC) [1] as the frequency band that ranges from $3.1 \mathrm{GHz}$ to $10.6 \mathrm{GHz}$, which is a $7.5 \mathrm{GHz}$ bandwidth (BW). Several planar UWB monopole antennas, which have the potential to meet such requirements, were reported in [2-5]. Due to the overlap of the currently allocated UWB frequency band with the communication systems such as Wireless Local Area Network (WLAN) bands in the $2.4 \mathrm{GHz}$ $(2.4-2.484 \mathrm{GHz}), \quad 5.2 \mathrm{GHz}(5.15-5.35 \mathrm{GHz})$, and $5.8 \mathrm{GHz}$ $(5.725-5.825 \mathrm{GHz})$ bands, and the World Interoperability for Microwave Access (WiMAX) system bands $2.5 \mathrm{GHz}$ (2.5-2.69 GHz), 3.5 GHz (3.4-3.69 GHz), and 5.8 GHz (5.25$5.825 \mathrm{GHz}$ ) [6]. Now, many systems operate across several frequency bands, requiring a band-notched or band-rejected function. Thus, it is desirable to design UWB antennas with band notch characteristics to avoid potential interferences from the other frequency bands. To overcome problems caused by this electromagnetic interference, several designs of UWB antennas with single or multiple notch functions have been proposed in recent literature [6-39]. Reviewing the literature shows that there are few ways for monopole planar antennas to achieve band-notched characteristics. The most popular approach is cutting different shaped slots from the radiating patch, from the ground plane, or from the feed line, that is, U-shaped slot [7], a Hilbert-curve shaped slot [8], cutting a wide line [9], T-shaped slot [10], defected ground structure (DGS) [11], semicircular slot [12], a bent slot or C-shaped slot [13-15], split ring in the ground plane [16], and slot line in the feed line [17]). Another way consists of loading diverse parasitic elements on the antenna, such as parasitic elements rear or near the radiating element [18-23], and near the feed line [24-33], to generate the band-notched 
feature, which acts as resonator when the length of strip is about a half or a quarter of the guided wavelength at the desired notch frequency. In reference [31], a band-notched characteristic has been achieved by coupling a pair of openloop resonators beside the feed line, in this reference, the author just notched the band for WLAN system. In reference [32], one set of band rejected structure with two C-shaped slots has been adopted to reject the lower WLAN band (5.15$5.35 \mathrm{GHz}$ ) and another one with two splits inverted resonators has been employed to reject the upper WLAN band (5.725$5.825 \mathrm{GHz}$ ). In reference [33], two splits rectangular ring resonators have been placed close to the microstrip line to reject the band 5.02-6.05 GHz. Additionally, a straight line slit has been etched on the radiating patch to reject the band 2.52-3.66 GHz; by using this technique, the control of this rejected band is limited by few key design parameters, and by the space restriction of the radiating patch to avoid this drawback and to get more freedom in designing, it is better to use another shape slit. In reference [34], only one notched band centered at $5.5 \mathrm{GHz}$ is achieved by etching a partial annular slot in the lower portion of a ring radiator. Most of UWB antennas have no more than two notched bands, and few of them have three notched bands [35-37], which reveal that potential interference from other narrow bands may still exist. So, to design an antenna for UWB applications with notching all the bands for WiMAX and WLAN systems is necessary. In reference [35], three parasitic resonant elements are placed near the ground plane to generate three notch frequency bands $3.26-3.71 \mathrm{GHz}, 5.15-$ $5.37 \mathrm{GHz}$, and $5.78-5.95 \mathrm{GHz}$; in this reference, the bands 2.4/2.5 GHz corresponding to WLAN and WiMAX have not been rejected, and the use of parasitic resonators leads to a more complex structure. In reference [36], a compact UWB antenna with triple band rejected characteristics is achieved with using a meander line split ring resonator, with using this technique three bands 3.15-3.75, 4.85-6.08, and $7.98-8.56 \mathrm{GHz}$ are rejected. The meander line split ring resonator used in this reference is complex compared to a conventional C-shaped slot structure. In reference [37], a pair of spiral loop resonators have been merged with radiating patch to create the first notched band in $3.3-3.7 \mathrm{GHz}$, in addition, two integrated microstrip resonators have been coupled with ground plane to generate the second and the third-notched bands in 5.2-5.4 GHz and 5.7-6 GHz. All the techniques can achieve good band notch characteristics, but some of the notched band structures are complex and difficult to design. In the designing of triple or multiband notch antenna, it is difficult to adjust and to control the frequency center of the notch bands in a limited space. Moreover, strong couplings between the band-notched characteristics designs for adjacent frequencies are the complication in achieving efficient triple band-notched UWB antenna. There are a lot of researches on UWB antennas with band-notched characteristics [6-39], but how to obtain high efficient bandnotched characteristics is still a challenging issue. The main problem of the band rejected function design is the difficulty of controlling bandwidth and the shifting of the notched band, especially for the case of antennas with several rejected band structures, without infecting other rejected bands.

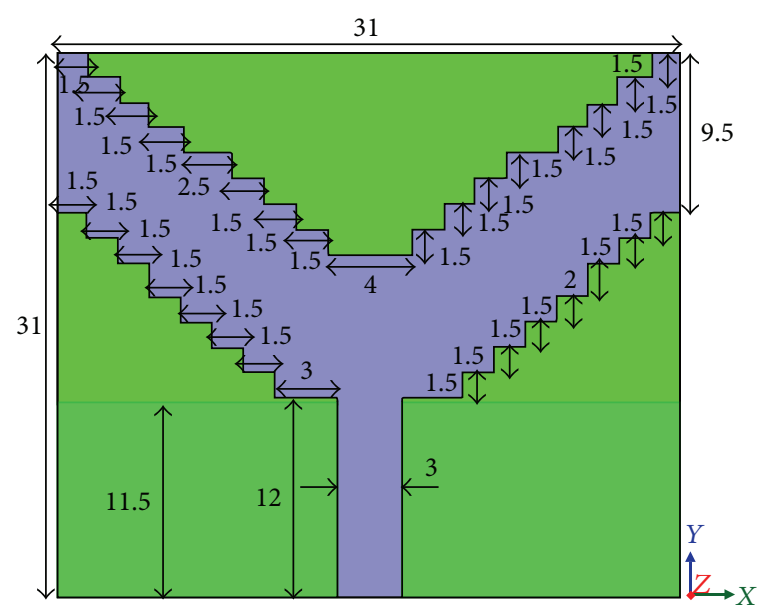

FIGURE 1: Geometry of the proposed UWB antenna without band rejected structure.

In the future, we expect that the shifting and the control of the frequency center and the bandwidth of the bandnotched frequency can be both important and useful in wireless communication systems. So, the aim of this paper is to design a low cost and simple structure UWB antenna with controllable triple band-notched characteristics and an independent control of the width and the shifting of the rejected bands. We propose a compact microstrip-fed planar UWB antenna with modified stair cased V-shaped radiating elements and partial ground plane. To simplify the adjustment of the parameters of the rejected band structures and to obtain high efficient band-notched characteristics, three simple rejected band structures are investigated in this paper. So, three frequency bands notched are achieved with the investigation of these structures; the first rejected band $(1.6-2.66 \mathrm{GHz})$ is achieved by inserting the vertical down Cshaped slot in the ground plane, two others rejected bands (3-4 GHz and $5.13-6.03 \mathrm{GHz}$ ) are realized by inserting two vertical up C-shaped slots in the radiator patch. The desired frequency notched bands can be easily achieved and flexibly controlled by adjusting the total length of the corresponding band-notched structure. The designed antenna with optimal dimensions was prototyped and measured. A comparison between experimental and simulated results of the voltage standing wave ratio is achieved. The remaining of this paper is organized as follows. Section 2 presents the configuration of the proposed antenna; parametric study is investigated in Section 3. The simulated and measured results are discussed in Section 4, and finally the conclusion is provided in Section 5.

\section{Antenna Configuration}

Figure 1 shows the geometry of the proposed compact planar UWB monopole antenna without rejecting band structures. The proposed UWB antenna is located on the $x-y$ plane and the normal direction is parallel to $z$-axis. This antenna is fabricated on a low-cost FR4 epoxy substrate with the 


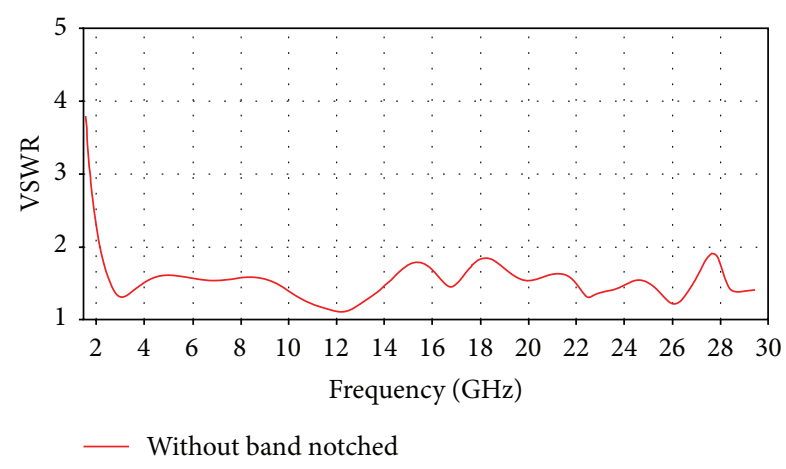

FIGURE 2: Simulated VSWR of the reference antenna without bandrejected characteristics.

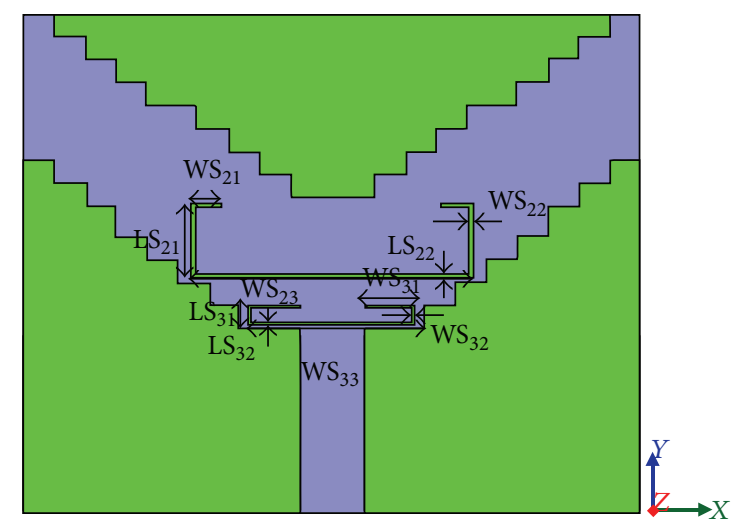

(a)

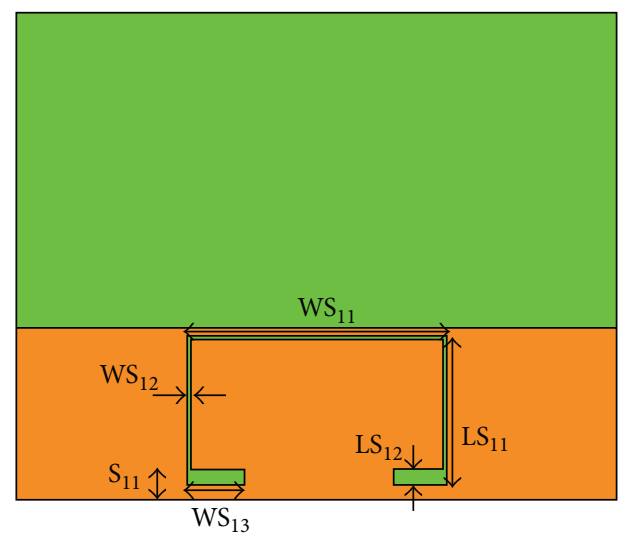

(b)

FIGURE 3: The geometry of the proposed triple band-notched antenna: (a) top view and (b) bottom view.

thickness of $1.6 \mathrm{~mm}$, relative dielectric constant of 4.4 , and loss tangent of 0.008 . On the front surface of the substrate of each UWB antenna, a modified stair cased V-shaped radiating element is printed, fed by a microstrip line $50 \Omega$ with $3 \mathrm{~mm}$ of width. The ground plane size is $31 \times 11.5 \mathrm{~mm}^{2}$, and the distance between the radiating patch to the ground plane printed on the back surface substrate is $0.5 \mathrm{~mm}$.

The simulated voltage standing wave ratio (VSWR) of the reference UWB antenna without band-rejected is presented in Figure 2. The parameters of the reference antenna are

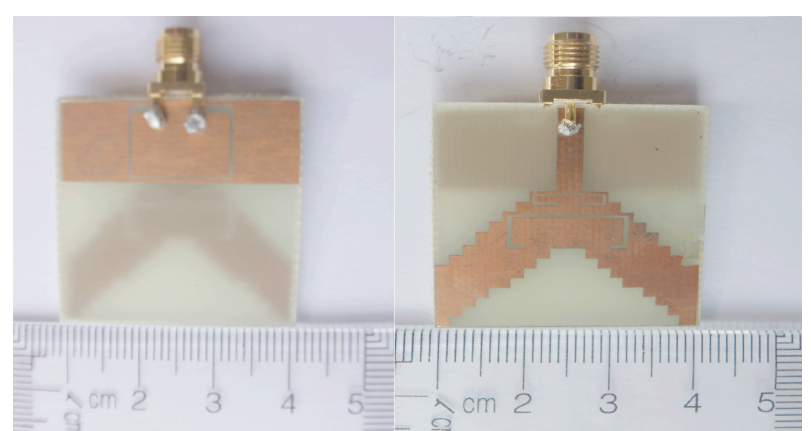

FIgURE 4: Top and bottom view of the fabricated sample of the proposed antenna.

optimized to get a VSWR that is less than 2 and to get stable radiation characteristics throughout the frequency band $2.1 \mathrm{GHz}$ to upper than $30 \mathrm{GHz}$.

To overcome the unwanted electromagnetic interferences of UWB communication systems with WLAN and WiMAX frequencies band, two half wavelength vertical up C-shaped slots are inserted in the radiating patch with a half wavelength vertical down C-shaped slot that is embedded in the ground plane. The geometry of the proposed triple bandnotched antenna is depicted in Figure 3. The HFSS software is employed to perform the design process.

The total length of each slot can be deduced by (1), which is based on the author's previous works like in [18]. The slots resonate at the corresponding band notching frequency, where its total length is equal to a half wavelength as follows:

$$
L_{\text {Total }}=\frac{c}{2 f_{\text {notch }} \sqrt{\varepsilon_{\text {eff }}}},
$$

where

$$
\varepsilon_{\mathrm{eff}}=\frac{\varepsilon_{r}+1}{2}
$$

And $L_{\text {Total }}$ denotes the total length of the corresponding slot; $\varepsilon_{\text {eff }}$ is the effective dielectric constant of the substrate; and $c$ is the speed of light in free space.

\section{Parametric Study}

A parametric study of the proposed triple band-notched UWB antenna was carried out in order to control the band rejection operation. It is necessary to control the notched bandwidths in practical application to obtain an effective band-notched UWB antenna. Therefore, the rejected bandwidths based on the dimensions of the corresponding notched band structure are studied. By adjusting the total length of each slot to be about a half-wavelength at the desired notched frequency, a destructive interference can take place, and triple band-notched characteristics at 2.2/3.54/5.68 GHz frequencies center are achieved. Details of the influence of each parameter on the proposed triple band-notched antenna will be studied in this section. The discussed parameter is changed, and the other parameters are kept unchanged. 


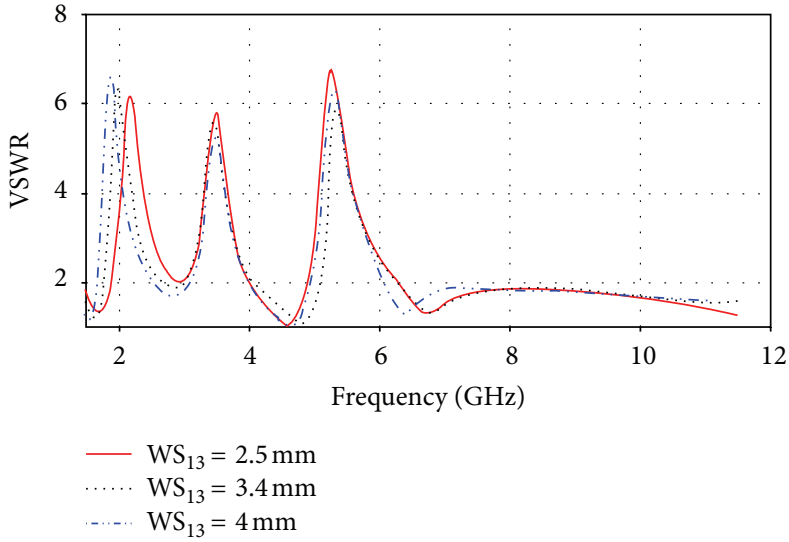

(a)

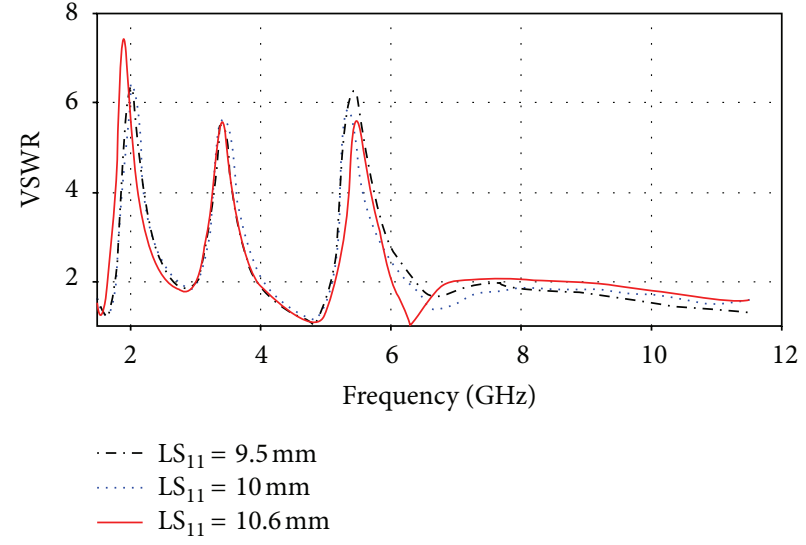

(b)

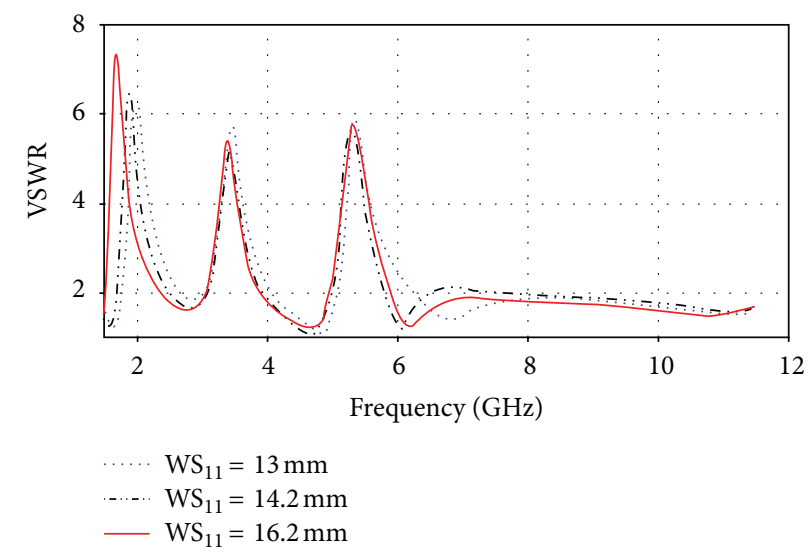

(c)

FigURE 5: The simulated VSWR of the proposed antenna: effects of some parameters on the $2.2 \mathrm{GHz}$ band-notched function, (a) WS ${ }_{13}$, (b) $\mathrm{LS}_{11}$, (c) $\mathrm{WS}_{11}$.

3.1. Controlling the First Rejected Band Generated by the Vertical down C-Shaped Slot. Figures 5(a), 5(b), and 5(c) show the simulated VSWR with changing $\mathrm{WS}_{13}, \mathrm{LS}_{11}$, and $\mathrm{WS}_{11}$ on the $2.2 \mathrm{GHz}$ frequency center band. When $\mathrm{WS}_{13}$ increases, the center of the first rejected band $2.2 \mathrm{GHz}$ shifts slightly for lower frequencies side: from $2.37 \mathrm{GHz}$ for $\mathrm{WS}_{13}$ $=2.5 \mathrm{~mm}$ to $2.1 \mathrm{GHz}$ for $\mathrm{WS}_{13}=4 \mathrm{~mm}$. We observe the same effect when $\mathrm{LS}_{11}$ increases: the center of the first rejected band shifts slightly from $2.2 \mathrm{GHz}$ for $\mathrm{LS}_{11}=9.5 \mathrm{~mm}$ to $2.16 \mathrm{GHz}$ for $\mathrm{LS}_{11}=10.6 \mathrm{~mm}$. In addition, the lower rejected bandwidth shifts slightly for lower frequencies side with increasing $\mathrm{WS}_{11}$ : from $2.2 \mathrm{GHz}$ for $\mathrm{WS}_{11}=13 \mathrm{~mm}$ to $2 \mathrm{GHz}$ for $\mathrm{WS}_{11}=$ $16.2 \mathrm{~mm}$. The first notched band width is decided by $\mathrm{WS}_{13}$, $\mathrm{LS}_{11}$, and $\mathrm{WS}_{11}$. On the other hand, we can observe that the parameters $\mathrm{WS}_{13}, \mathrm{LS}_{11}$, and $\mathrm{WS}_{11}$ have small influences for the two other rejected bands $3.54 \mathrm{GHz}$ and $5.68 \mathrm{GHz}$.

3.2. Controlling the Second Rejected Band Generated by the Upper Vertical up C-Shaped Slot. Figures 6(a), 6(b), and 6(c) show the simulated VSWR with changing $\mathrm{WS}_{21}, \mathrm{LS}_{21}$, and $\mathrm{WS}_{23}$ on the second rejected band $3.54 \mathrm{GHz}$. When $\mathrm{WS}_{21}$ increases, the center of the second rejected band $3.54 \mathrm{GHz}$ shifts for lower frequencies side: from $3.54 \mathrm{GHz}$ for $\mathrm{WS}_{21}=$ $1.4 \mathrm{~mm}$ to $2.6 \mathrm{GHz}$ for $\mathrm{WS}_{21}=5.9 \mathrm{~mm}$. We observe the same effect when $\mathrm{LS}_{21}$ increases: the center of the second rejected band $3.54 \mathrm{GHz}$ shifts from $3.9 \mathrm{GHz}$ for $\mathrm{LS}_{21}=2.2 \mathrm{~mm}$ to $3.54 \mathrm{GHz}$ for $\mathrm{LS}_{21}=4.7 \mathrm{~mm}$. In addition, the second rejected bandwidth becomes wider when $\mathrm{WS}_{23}$ increases, and the center of the lower rejected band shifts for lower frequencies side: the width of the lower rejected band increases from $0.45 \mathrm{GHz}$ for $\mathrm{WS}_{23}=10.8 \mathrm{~mm}$ to $1 \mathrm{GHz}$ for $\mathrm{WS}_{23}=13.8 \mathrm{~mm}$. From the discussion above, the parameters $\mathrm{WS}_{21}, \mathrm{LS}_{21}$, and $\mathrm{WS}_{23}$ are the most important parameters of second notched bandwidth $3.54 \mathrm{GHz}$, and it can be independently adjusted by changing these three parameters. On the other hand, we can observe that the parameters $\mathrm{WS}_{21}, \mathrm{LS}_{21}$, and $\mathrm{WS}_{23}$ have very small influences for the $2.2 \mathrm{GHz}$ and $5.68 \mathrm{GHz}$ rejected bands.

3.3. Controlling the Third Rejected Band Generated by the Lower Vertical up C-Shaped Slots. Figures 7(a), 7(b), and 7 (c) show the simulated VSWR with changing $\mathrm{WS}_{31}, \mathrm{LS}_{31}$, and $\mathrm{WS}_{33}$ on the third rejected band $5.68 \mathrm{GHz}$. When $\mathrm{WS}_{31}$ increases the center of the third rejected band shifts for lower frequencies side: from $5.91 \mathrm{GHz}$ for $\mathrm{WS}_{31}=2.4 \mathrm{~mm}$ to $5.48 \mathrm{GHz}$ for $\mathrm{WS}_{31}=3 \mathrm{~mm}$. We observe the same effect when $\mathrm{LS}_{31}$ increases: the center of the third rejected band shifts from $5.82 \mathrm{GHz}$ for $\mathrm{LS}_{31}=0.65 \mathrm{~mm}$ to $5.42 \mathrm{GHz}$ for $\mathrm{LS}_{31}=1.55 \mathrm{~mm}$. In addition, the third rejected bandwidth 


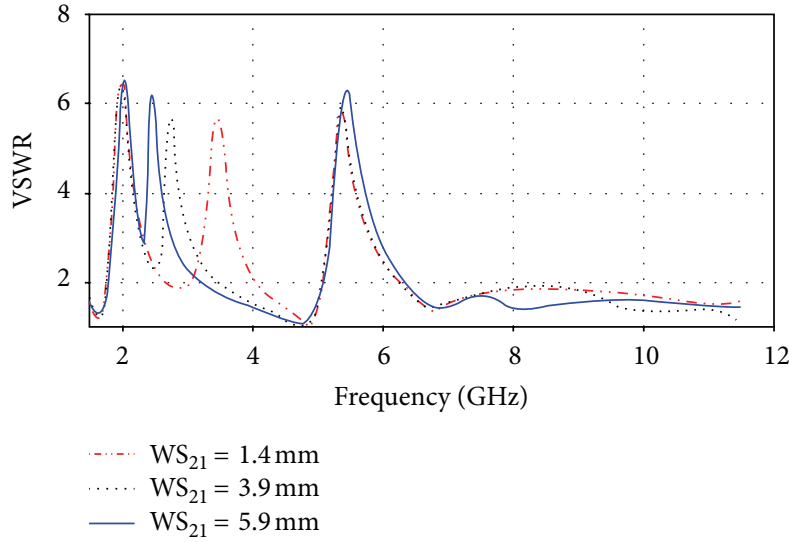

(a)

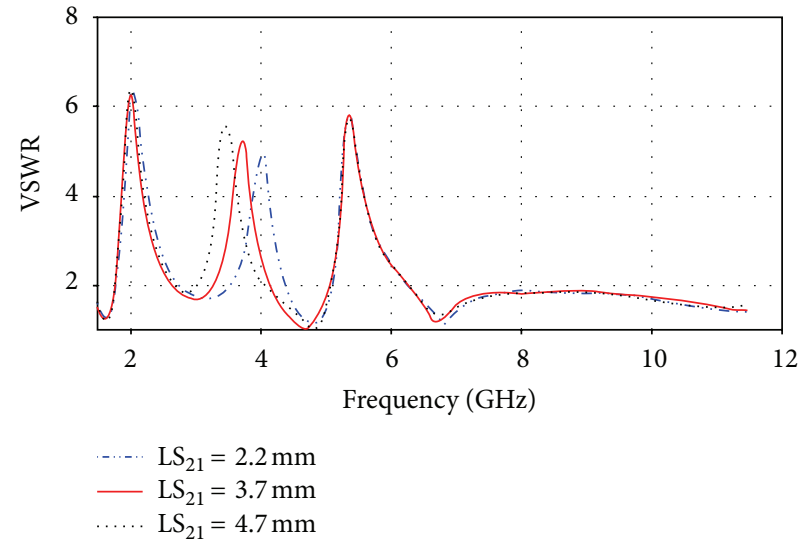

(b)

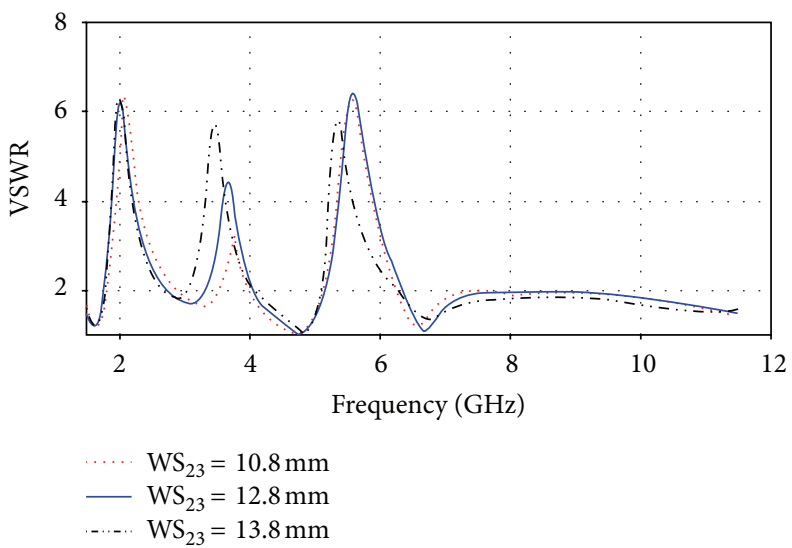

(c)

FIGURE 6: The simulated VSWR of the proposed antenna: effects of some parameters on the $3.54 \mathrm{GHz}$ band-notched function, $(\mathrm{a})$ WS ${ }_{21}$, (b) $\mathrm{LS}_{21}$, (c) $\mathrm{WS}_{23}$.

TABLE 1: The optimized dimensions of the slots investigated in the proposed antenna.

\begin{tabular}{lccccccccc}
\hline Parameter & $\mathrm{WS}_{13}$ & $\mathrm{LS}_{11}$ & $\mathrm{WS}_{11}$ & $\mathrm{WS}_{21}$ & $\mathrm{LS}_{21}$ & $\mathrm{WS}_{23}$ & $\mathrm{WS}_{31}$ & $\mathrm{LS}_{31}$ & $\mathrm{WS}_{33}$ \\
\hline Value $(\mathrm{mm})$ & 3.4 & 10 & 13 & 1.4 & 4.7 & 13.8 & 2.7 & 1.25 & 8.3 \\
\hline
\end{tabular}

becomes wider when $\mathrm{WS}_{33}$ increases, and the center of the third rejected band shifts for lower frequencies side: the width of the lower rejected band increases from $0.44 \mathrm{GHz}$ for $\mathrm{WS}_{33}$ $=7.3 \mathrm{~mm}$ to $1.18 \mathrm{GHz}$ for $\mathrm{WS}_{33}=8.3 \mathrm{~mm}$. From the discussion above, we can control the shifted band-notched frequency and the enhanced width of the third band notch $5.68 \mathrm{GHz}$ by varying the parameters $\mathrm{WS}_{31}, \mathrm{LS}_{31}$, and $\mathrm{WS}_{33}$, and it can be independently adjusted by changing these parameters. On the other hand, we can observe that the parameters $\mathrm{WS}_{31}$, $\mathrm{LS}_{31}$, and $\mathrm{WS}_{33}$ have very small influences for the two lower rejected bands $2.2 \mathrm{GHz}$ and $3.54 \mathrm{GHz}$. In summary, the longer the length of the slots and resonators gets, the lower the notched band frequency becomes.

\section{Results and Discussion}

The proposed UWB antenna with triple band-notched characteristics has been fabricated and measured. The photograph of the prototyped antenna is shown in Figure 4. The optimized dimensions of the band-notched structures used in measurement are depicted in Table 1.

4.1. VSWR Measurement. Figure 8 shows the measured and simulated voltage standing wave ratio (VSWR) results for the proposed antenna with bands notched characteristics, an excellent agreement between them is observed. It can be seen that the measured notched frequencies and the 


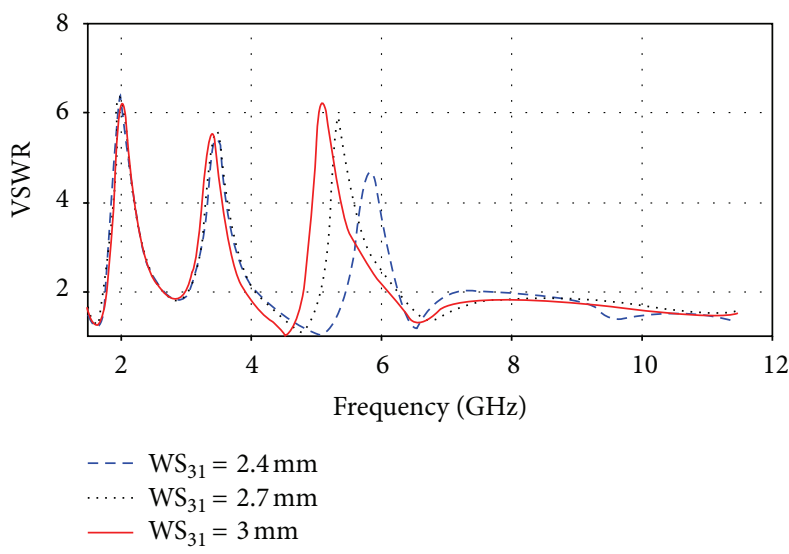

(a)

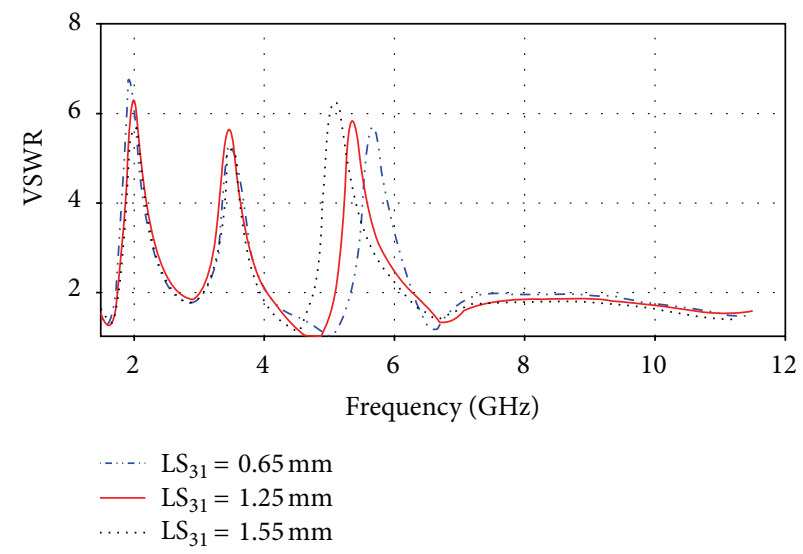

(b)

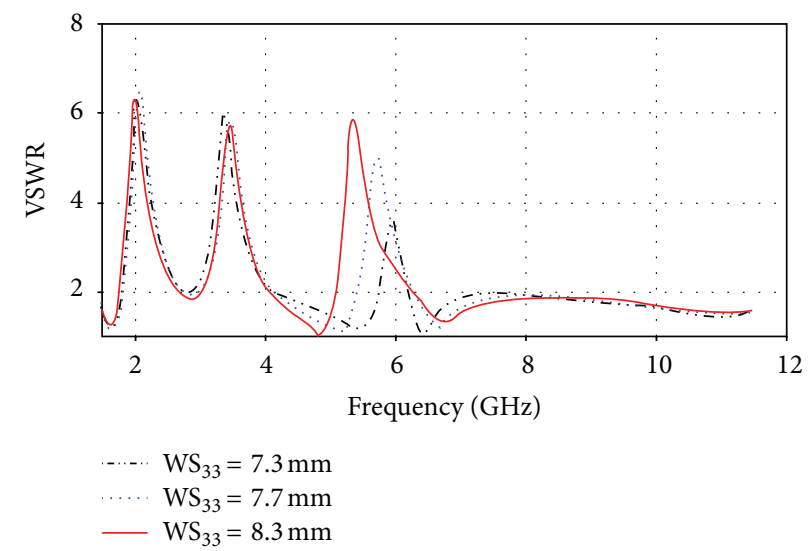

(c)

FIGURE 7: The simulated VSWR of the proposed antenna: effects of some parameters on the $5.68 \mathrm{GHz}$ band-notched function, (a) WS ${ }_{31}$, (b) $\mathrm{LS}_{31}$, (c) $\mathrm{WS}_{33}$.

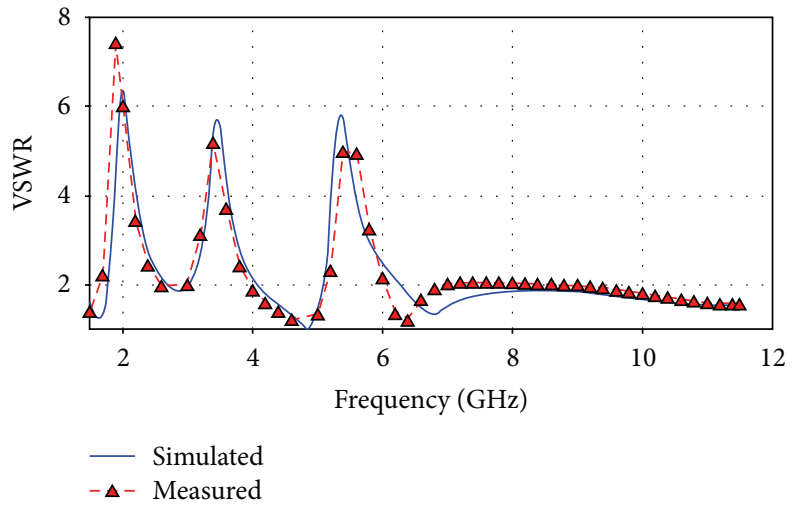

FIGURE 8: The measured and simulated VSWR of the proposed triple band-notched antenna.

TABLE 2: The rejected bands achieved with the proposed antenna.

\begin{tabular}{lccc}
\hline Results & & Frequency bands & \\
& 1st rejected band & 2nd rejected band & 3rd rejected band \\
\hline Simulated & $1.7-2.7 \mathrm{GHz}$ & $3.04-4.04 \mathrm{GHz}$ & $5.09-6.27 \mathrm{GHz}$ \\
Measured & $1.6-2.66 \mathrm{GHz}$ & $3-4 \mathrm{GHz}$ & $5.13-6.03 \mathrm{GHz}$ \\
\hline
\end{tabular}




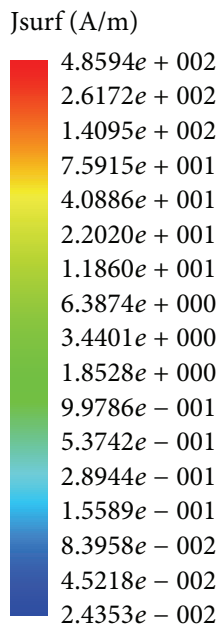

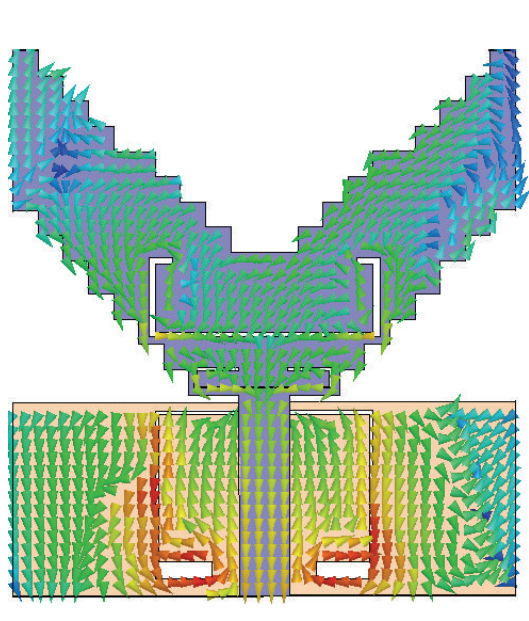

(a)

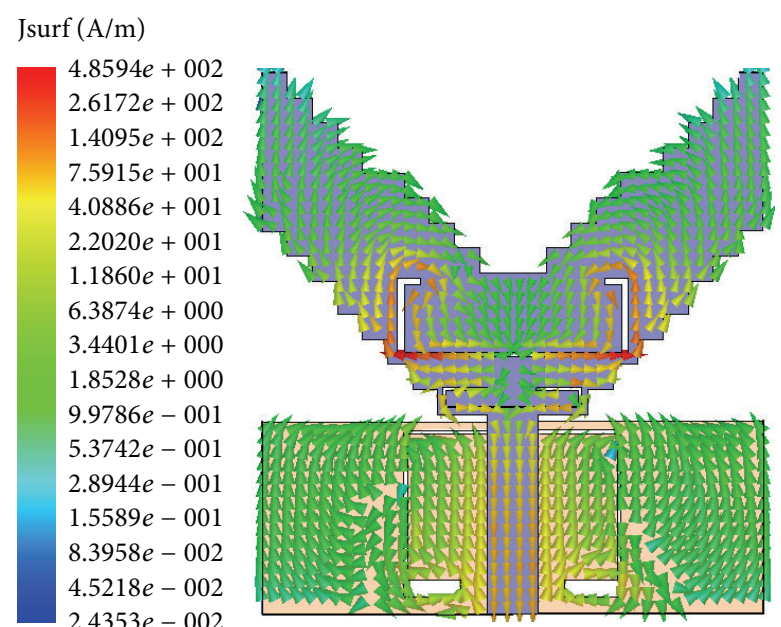

(b)

Jsurf $(\mathrm{A} / \mathrm{m})$
$4.8582 e+002$
$2.6166 e+002$
$1.4092 e+002$
$7.5900 e+001$
$4.0879 e+001$
$2.2017 e+001$
$1.1858 e+001$
$6.3865 e+000$
$3.4397 e+000$
$1.8526 e+000$
$9.9776 e-001$
$5.3738 e-001$
$2.8943 e-001$
$1.5588 e-001$
$8.3955 e-002$
$4.5217 e-002$
$2.4353 e-002$

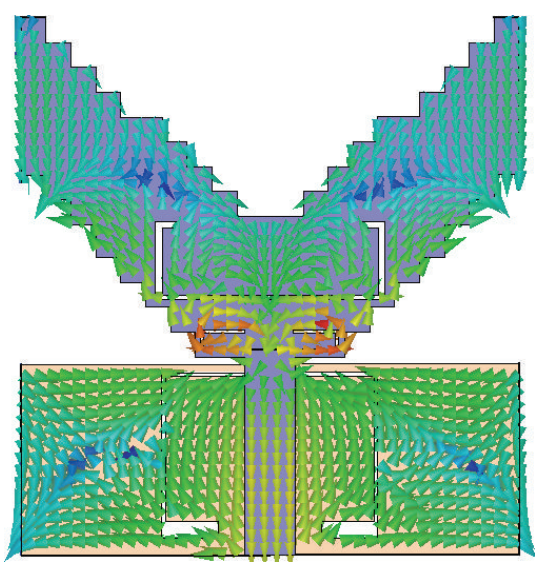

(c)

FIgURE 9: The current distribution on the proposed antenna at (a) $2.2 \mathrm{GHz}$, (b) $3.54 \mathrm{GHz}$, (c) $5.68 \mathrm{GHz}$.

bandwidths for each of the notched band are very suitable to suppress the disturbances from WLAN and WiMAX systems. The measured frequency range covers commercial UWB band $(3.1-10.6 \mathrm{GHz})$ and rejects three frequencies bands $1.6-$ $2.66 \mathrm{GHz}$ (49.76\%), 3-4 GHz (28.57\%), and $5.13-6.03 \mathrm{GHz}$ (16.12\%); see Table 2 .

4.2. Current Distribution. Figures 9(a), 9(b), and 9(c) show the current distribution on our proposed antenna with triple band-notched characteristics at frequencies $2.2 \mathrm{GHz}$, $3.54 \mathrm{GHz}$, and $5.68 \mathrm{GHz}$ for the optimal design. A large current distribution around the edges of the slots is observed. In this case, destructive interference for the excited surface currents in the antenna will occur, which causes the antenna to be nonresponsive at those frequencies. At $2.2 \mathrm{GHz}$, a large current that is distributed around the vertical down C-shaped slot and a very small current that flowed along the two other slots with vertical up C-shaped are seen, which indicates that the changed dimensions of the vertical down C-shaped slot embedded in the ground plane have no effects on the two other upper rejected bands $3.54 \mathrm{GHz}$ and
$5.68 \mathrm{GHz}$. At $3.54 \mathrm{GHz}$, the current distribution mainly flows along the longest vertical up C-shaped slot embedded in the radiating element, while the currents around the two other slots are very small. In this way, the adjusted size for the longest vertical up $\mathrm{C}$-shaped slot embedded in the radiating element does not affect the $2.2 \mathrm{GHz}$ and $5.68 \mathrm{GHz}$ frequency bands. At $5.68 \mathrm{GHz}$, the current distributions mainly flow along the shortest vertical up C-shaped slot embedded in the radiating element, while the currents around the other two are very small. In this way, the adjusted size for the shortest vertical up C-shaped slot embedded in the radiating element does not affect the $2.2 \mathrm{GHz}$ and $3.54 \mathrm{GHz}$ frequency bands.

4.3. Radiation Pattern. Figure 10 shows the normalized farfield radiation patterns for the proposed antenna in two principle planes at different operating frequencies $1.5 \mathrm{GHz}$, $4.5 \mathrm{GHz}, 7.5 \mathrm{GHz}, 8.5 \mathrm{GHz}$, and $10 \mathrm{GHz}$. At higher frequencies, the radiation pattern deteriorates because the equivalent radiating area changes with frequency over UWB; unequal phase distribution and significant magnitude of 


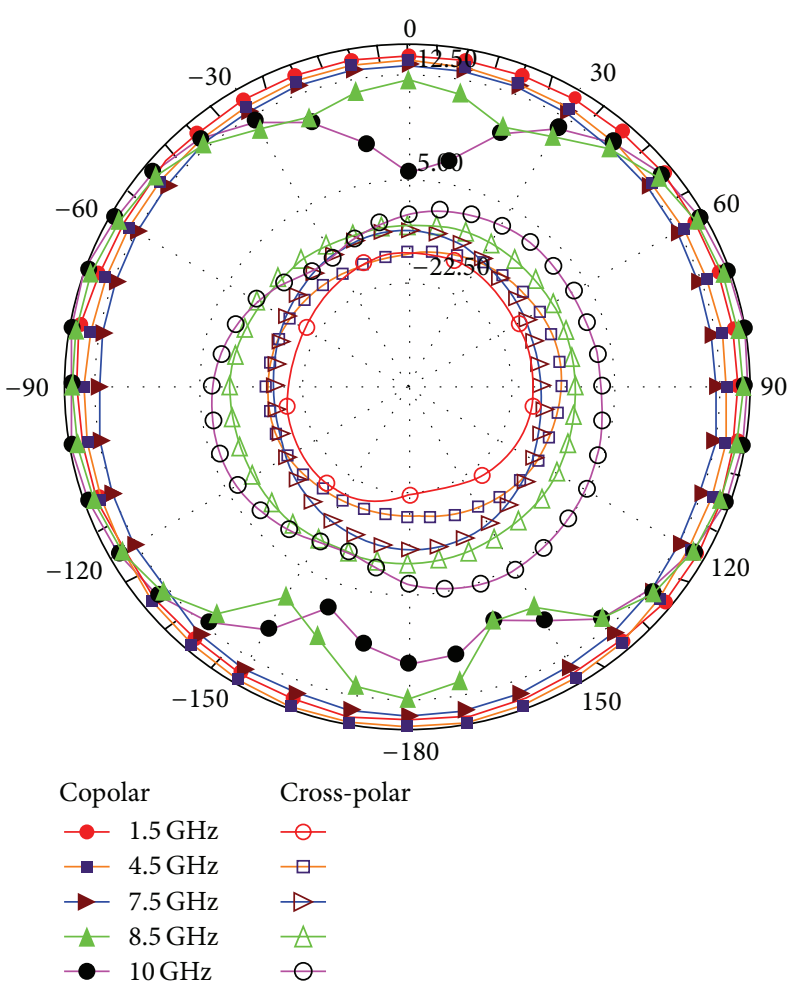

(a)

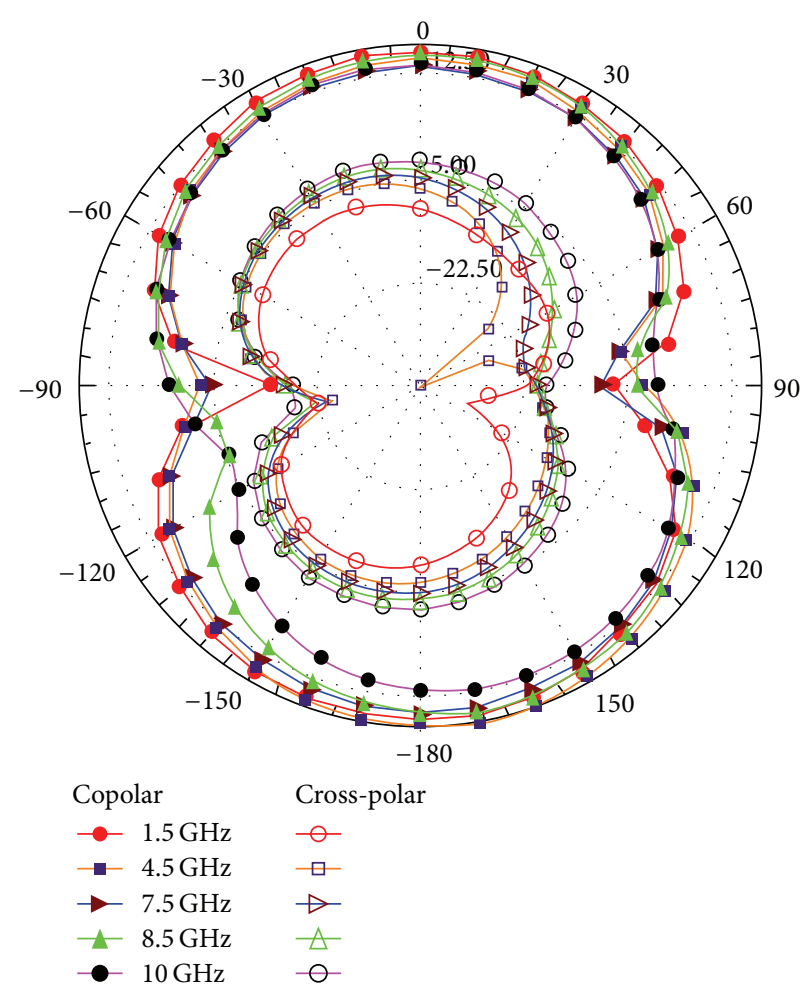

(b)

FIGURE 10: Radiation patterns at some frequencies: (a) $x-z$ plane (H plane) and (b) $y$ - $z$ plane (E plane).

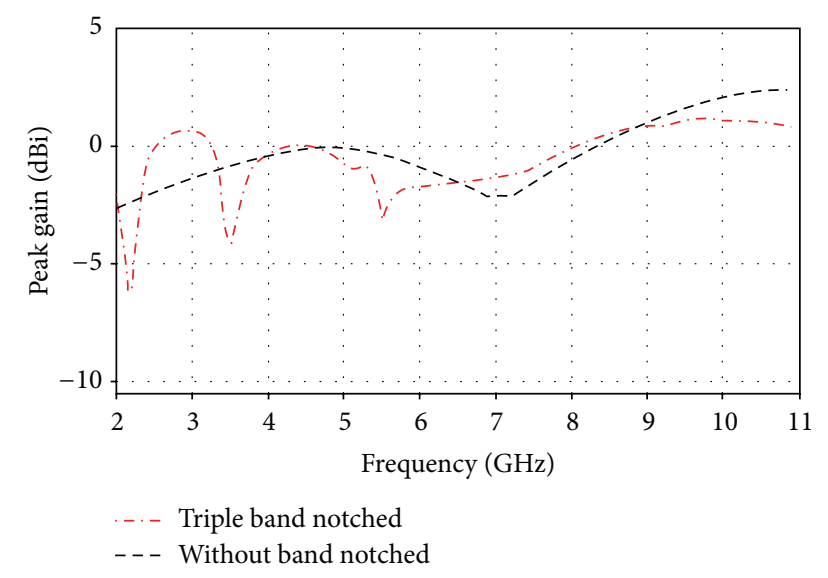

FIGURE 11: Peak gain of the proposed antenna with and without notched band structure.

higher order modes also play a part in the deterioration of the radiation pattern. Omnidirectional characteristics and radiation bandwidth can be improved if the ground plane length is approximately the same size as that of the radiating structure width. Also they can be further improved by using a thin substrate or a substrate with low dielectric constant [38]. The proposed triple band-notched antenna has nearly omnidirectional radiation characteristic in the $\mathrm{H}$ plane copolar radiation pattern and becomes faintly directional with increasing the frequency. The E-plane copolar radiation patterns over operating frequencies are roughly symmetric and have two main lobes. In addition, we can note that the cross-polarization level plane increases marginally with increasing the frequency.

4.4. Peak Gain. The comparison of the peak gain of the proposed antenna with that of the one without band-notched structures is shown in Figure 11. The peak gain of the proposed triple band-notched antenna almost follows the peak gain of the reference antenna without band-notched structures over the UWB frequency band, except in the notched bands. Three significant drops of the peak gain can be observed in the operating frequency. The peak gain decreases drastically to $-6.23 /-5.06 /-3.20 \mathrm{dBi}$ at around the notched bands which demonstrates that the band-notched function is good.

4.5. Group Delay and Transfer Function. Group delay is an important parameter to characterize the degree of distortion of the pulse signal for UWB impulse-based system. It is desired that the group delay response is stable over the UWB frequency band. In addition, the shape of the transmitted pulse should not be distorted [39]. Two identical antennas are arranged face to face at a distance of $30 \mathrm{~cm}$ which achieves the far-field condition of the antenna. The group delay of 


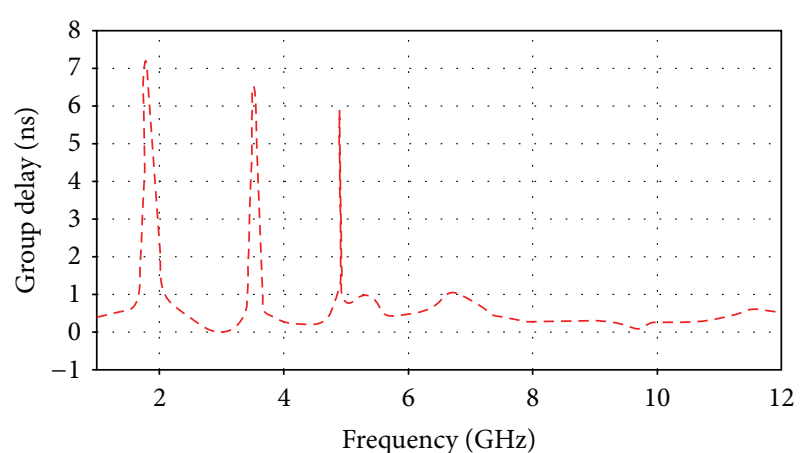

FIGURE 12: Group delay of the proposed triple band-notched antenna.

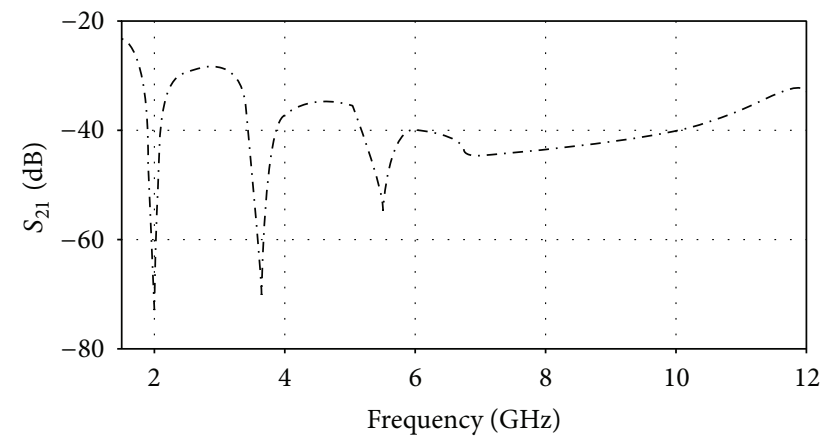

FIGURE 13: Transfer function of the proposed triple band-notched antenna.

the antenna system is shown in Figure 12. The group delay variation of the proposed antenna is very small, which is less than $1 \mathrm{~ns}$ in the pass band. However, in the notched bands, the group delay exceeds $5.5 \mathrm{~ns}$. The characteristic of the group delay indicates that the phase of the antenna is linear in the far field and the pulse signal is not distorted between transmitting and receiving antennas in the pass band. The magnitude of the transfer function has also little variation over the operating band except in the notched bands, as shown in Figure 13. Apart from the notched bands, the group delay and transfer function show slightly small variations, indicating that the proposed design is suitable for UWB applications.

At last, in order to reduce potential interferences between UWB systems with WiMAX and WLAN systems, we have exploited three notched bands structures in a proposed UWB antenna for rejecting three frequency bands and adjusting of their parameters influencing only the related rejected band; the rest of the UWB frequency band remains unaffected which offers an autonomous selection and control of the rejected band and bandwidth.

\section{Conclusion}

To minimize the potential interferences between the UWB communication systems with the WiMAX and WLAN systems, simple, low cost, and compact printed monopole antenna with controllable triple band-notched characteristics is proposed and investigated. Two different vertical up Cshaped slots with a vertical down C-shaped slot are embedded in the radiating patch and in the ground plane, respectively, for rejecting WiMAX and WLAN frequency bands. By simply adjusting the total length and width of the corresponding band-notched structure, the rejected frequency bands can be independently controlled. Finally, a UWB antenna with controllable triple band rejected characteristics is successfully simulated, prototyped, and measured, showing a near omnidirectional radiation pattern, a stable peak gain, and small group delay and transfer function variation over the whole band except in the notched frequency bands. Consequently, the advantages of simple structure, compact size, easy to fabricate, and excellent performances make this antenna a good candidate for practical UWB applications.

\section{Conflict of Interests}

The authors declare that there is no conflict of interests regarding the publication of this paper.

\section{References}

[1] Federal Communications Commission, "Revision of part 15 of the commission's rules regarding ultra-wideband transmission system from 3. 1 to 10. $6 \mathrm{GHz}$," in Federal Communications Commission, pp. 98-153, ET-Docket, Washington, DC, USA, 2002.

[2] R. Azim, M. T. Islam, and N. Misran, "Microstrip line-fed printed planar monopole antenna for UWB applications," The Arabian Journal of Sciences and Engineering, vol. 38, pp. 24152422, 2013.

[3] A. K. Gautam, S. Yadav, and B. K. Kanaujia, "A CPW-Fed compact UWB microstrip antenna," IEEE Antennas and Wireless Propagation Letters, vol. 12, pp. 151-154, 2013.

[4] A. A. Adam, S. K. A. Rahim, K. G. Tan, and A. W. Reza, "Design of 3.1-12 GHz printed elliptical disc monopole antenna with half circular modified ground plane for UWB application," Wireless Personal Communications, vol. 69, pp. 535-549, 2013.

[5] R. Gonçalves, P. Pinho, and N. B. Carvalho, "Compact, frequency reconfigurable, printed monopole antenna," International Journal of Antennas and Propagation, Article ID 602780, 2012.

[6] D.-O. Kim, N.-I. Jo, H.-A. Jang, and C.-Y. Kim, "Design of the ultrawideband antenna with a quadruple-band rejection characteristics using a combination of the complementary split ring resonators," Progress in Electromagnetics Research, vol. 112, pp. 93-107, 2011.

[7] X. Kang, H. Zhang, Z. Li et al., "A band-notched UWB printed half elliptical ring monopole antenna," Progress in Electromagnetics Research C, vol. 35, pp. 23-33, 2013.

[8] A. Karmakar, R. Ghatak, U. Banerjee, and D. R. Poddar, "An UWB antenna using modified Hilbert curve slot for dual band notch characteristics," Journal of Electromagnetic Waves and Applications, vol. 27, no. 13, pp. 1620-1631, 2013.

[9] L. Bing and J. S. Hong, "Design of two novel dual bandnotched UWB antennas," International Journal of Antennas AndPropagation, vol. 2012, Article ID 303264, 7 pages, 2012. 
[10] N. Ojaroudi and M. Ojaroudi, "Novel design of dual bandnotched monopole antenna with bandwidth enhancement for UWB applications," IEEE Antennas and Wireless Propagation Letters, vol. 12, pp. 698-701, 2013.

[11] S. Soltani, M. Azarmanesh, P. Lotfi, and G. Dadashzadeh, “Two novel very small monopole antennas having frequency band notch function using DGS for UWB application," International Journal of Electronics and Communications, vol. 65, no. 1, pp. 8794, 2011.

[12] T. Li, H. Q. Zhai, C. Zhu, L. Li, C. H. Liang, and Y. F. Han, "Design and analysis of compact printed dual band-notched ultrawideband (UWB) antenna," Journal of Electromagnetic Waves and Applications, vol. 27, no. 5, pp. 560-571, 2013.

[13] S. M. Zhang, F. S. Zhang, W. Z. Li, T. Quan, and H. Y. Wu, "A compact UWB monopole antenna with WiMAX and WLAN band rejections," Progress in Electromagnetics Research Letters, vol. 31, pp. 159-168, 2012.

[14] P. Gao, L. Xiong, J. Dai, S. He, and Y. Zheng, "Compact printed wide-slot UWB antenna with $3.5 / 5.5-\mathrm{GHz}$ dual band-notched characteristics," IEEE Antennas and Wireless Propagation Letters, vol. 12, pp. 983-986, 2013.

[15] S. K. Mishra, R. K. Gupta, A. Vaidya, and J. Mukherjee, "Lowcost, compact printed circular monopole UWB antenna with 3.5/5.5-GHz dual band-notched characteristics," Microwave and Optical Technology Letters, vol. 54, no. 1, pp. 242-246, 2012.

[16] J. Kim, N. Kim, and S. Lee, "A broadband antenna using the modified ground plane with a complementary split ring resonator for $5-\mathrm{GHz}$ WLAN band-notched performance," Microwave and Optical Technology Letters, vol. 54, no. 1, pp. 1-3, 2012.

[17] M. A. Amin, "Design of a CPW-fed band-notched UWB antenna using a feeder-embedded slotline resonator," International Journal of Antennas and Propagation, vol. 2008, Article ID 564317, 2008.

[18] M. Xie, Q. Guo, and Y. Wu, "Design of a miniaturized UWB antenna with band-notched and high frequency rejection capability," Journal of Electromagnetic Waves and Applications, vol. 25, no. 8-9, pp. 1103-1112, 2011.

[19] W. Junhui, Y. Yingzeng L Xianglong, and W. Tuo, “Trapezoid UWB antenna with dual band notched characteristics for WiMAX/WLAN bands," Electronics Letters, vol. 49, no. 11, 2013.

[20] S.-J. Wu and J.-H. Tarng, "Planar band-notched ultra-wideband antenna with square-looped and end-coupled resonator," IET Microwaves, Antennas and Propagation, vol. 5, no. 10, pp. 12271233, 2011.

[21] M. Almalkawi and V. Devabhaktuni, "Ultrawideband antenna with triple band-notched characteristics using closed-loop ring resonators," IEEE Antennas and Wireless Propagation Letters, vol. 10, pp. 959-962, 2011.

[22] Q. Q. Xing, H. C. Yang, D. K. Liu, and L. Yang, "Dual and triband-notched ultrawideband (UWB) antennas using compact composite resonators," Progress in Electromagnetics Research Letters, vol. 42, pp. 177-185, 2013.

[23] X. L. Liu, Y. Z. Yin, J. H. Wang, and J. J. Xie, "Compact dual band-notched UWB antenna with parasitic micro-strip lines and t-shape stub," Progress in Electromagnetics Research C, vol. 41, pp. 55-66, 2013.

[24] C.-C. Lin, P. Jin, and R. W. Ziolkowski, "Single, dual and triband-notched ultrawideband (UWB) antennas using capacitively loaded loop (CLL) resonators," IEEE Transactions on Antennas and Propagation, vol. 60, no. 1, pp. 102-109, 2012.
[25] L. Tong, Z. Huiqing, L. Guihong, L. Long, and L. Changhong, "Compact UWB band-notched antenna design using interdigital capacitance loading loop resonator," IEEE Antennas and Wireless Propagation Letters, vol. 11, pp. 724-727, 2012.

[26] T. Li, F. F. Huo, H. Q. Zhai, and C. H. Liang, "Compact ultrawideband antenna with sharp band-notched characteristics for WiMax and WLAN," Electronics Letters, vol. 48, no. 22, 2012.

[27] S. K. Mishra and J. Mukherjee, "Compact printed dual bandnotched U-shape UWB antenna," Progress In Electromagnetics Research C, vol. 27, pp. 169-181, 2012.

[28] X. H. Wu and Q. X. Chu, "Compact ultra-wideband antenna with dual sharp notch-bands using integrated bandstop filter," in Proceedings of the Asia-Pacific Conference on Antennas and Propagation, pp. 27-29, IEEE Press, Singapore, August 2012.

[29] W. Jiang and W. Che, "A novel UWB antenna with dual notched bands for WiMAX and WLAN applications," IEEE Antennas and Wireless Propagation Letters, vol. 11, pp. 293-296, 2012.

[30] A. Khalilzadeh, A. E. C. Tan, and K. Rambabu, "Design of an integrated UWB antenna with dual band notch characteristics," International Journal of Electronics and Communications, vol. 67, pp. 433-437, 2013.

[31] L. Tong, Z. Huiqing, L. Long, L. Changhong, and H. Yinfu, "Compact UWB antenna with tunable band-notched characteristic based on microstrip open-loop resonator," IEEE Antennas and Wireless Propagation Letters, vol. 11, pp. 1584-1587, 2012.

[32] G. Yang, Q. X. CHU, and T. G. Huang, "A compact UWB antenna with sharp dual band-notched characteristics for lower and upper WLAN band," Progress in Electromagnetics Research C, vol. 29, pp. 135-148, 2012.

[33] L. Xiong and P. Gao, "Dual-band planar monopole antenna for bluetooth and UWB applications with WiMAX and WLAN band-notched," Progress in Electromagnetics Research Letters, vol. 28, pp. 183-194, 2012.

[34] R. Azim and M. T. Islam, "Compact planar UWB antenna with band notched characteristics for WLAN and DSRC," Progress in Electromagnetics Research Letters, vol. 133, pp. 391-406, 2013.

[35] M. T. Islam, R. Azim, and A. T. Mobashsher, "Triple bandnotched planar UWB antenna using parasitic strips," Progress in Electromagnetics Research, vol. 129, pp. 161-179, 2012.

[36] J. Y. Kim, B. Oh, N. Kim, and S. Lee, "Triple band-notched UWB antenna based on complementary meander line SRR," Electronics Letters, vol. 48, no. 15, 2012.

[37] S. Natarajamani, K. B. Santanu, and K. P. Sarat, "A triple band notched planar antenna for UWB applications," Journal of Electromagnetic Waves and Applications, vol. 27, no. 9, pp. 11781186, 2013.

[38] S. K. Mishra, R. Gupta, A. Vaidya, and J. Mukherjee, "Printed fork shaped dual band monopole antenna for bluetooth and UWB applications with 5.5GHZ WLAN band notched characteristics," Progress In Electromagnetics Research C, vol. 22, pp. 195-210, 2011.

[39] D. Zhou, S. Gao, F. Zhu, R. A. Abd-Alhameed, and J. D. $\mathrm{Xu}$, "A simple and compact planar ultra wide-band antenna with single or dual band-notched characteristics," Progress in Electromagnetics Research, vol. 123, pp. 47-65, 2012. 

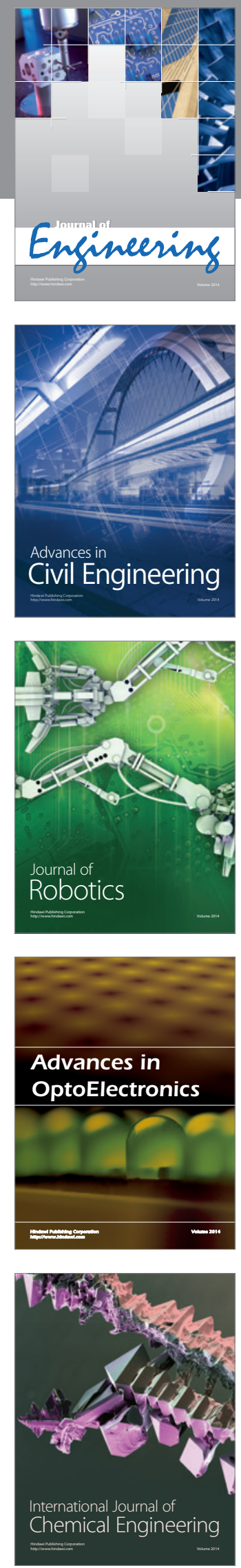

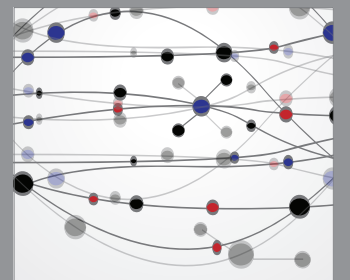

The Scientific World Journal
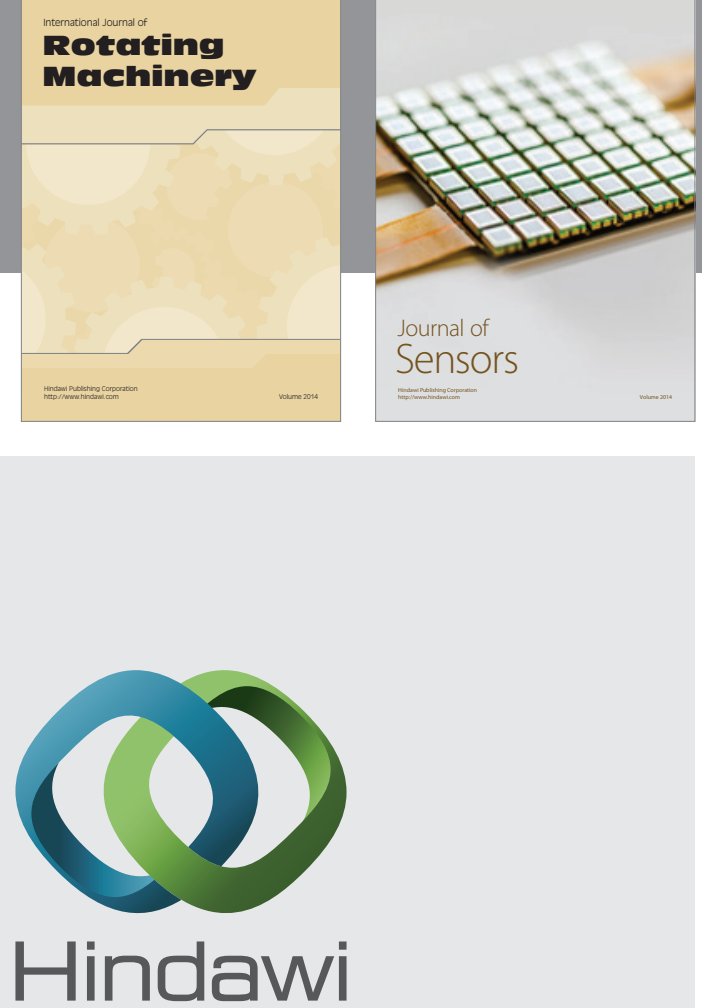

Submit your manuscripts at http://www.hindawi.com
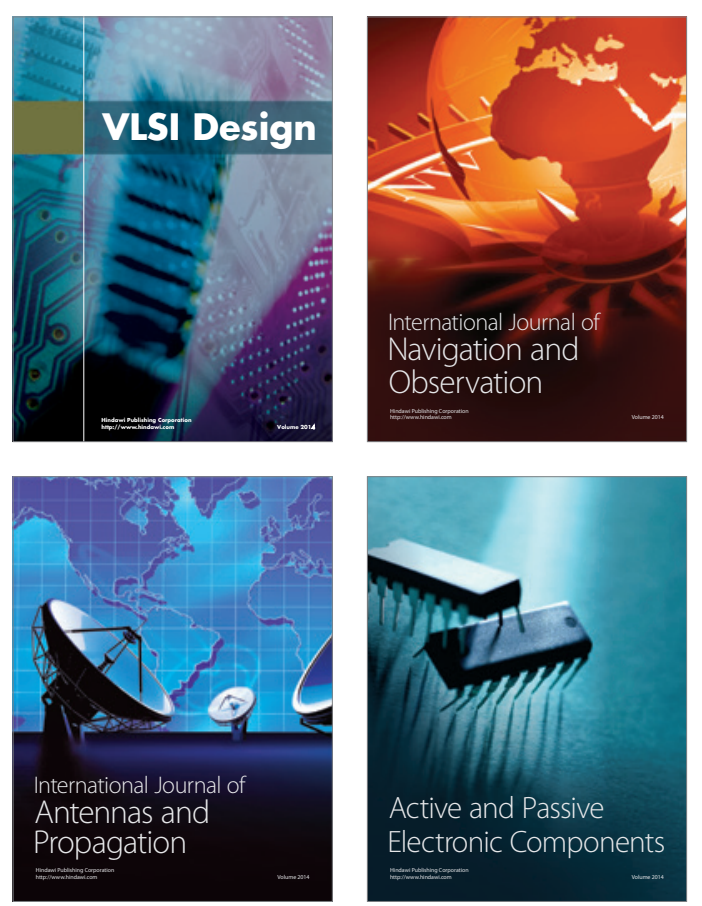
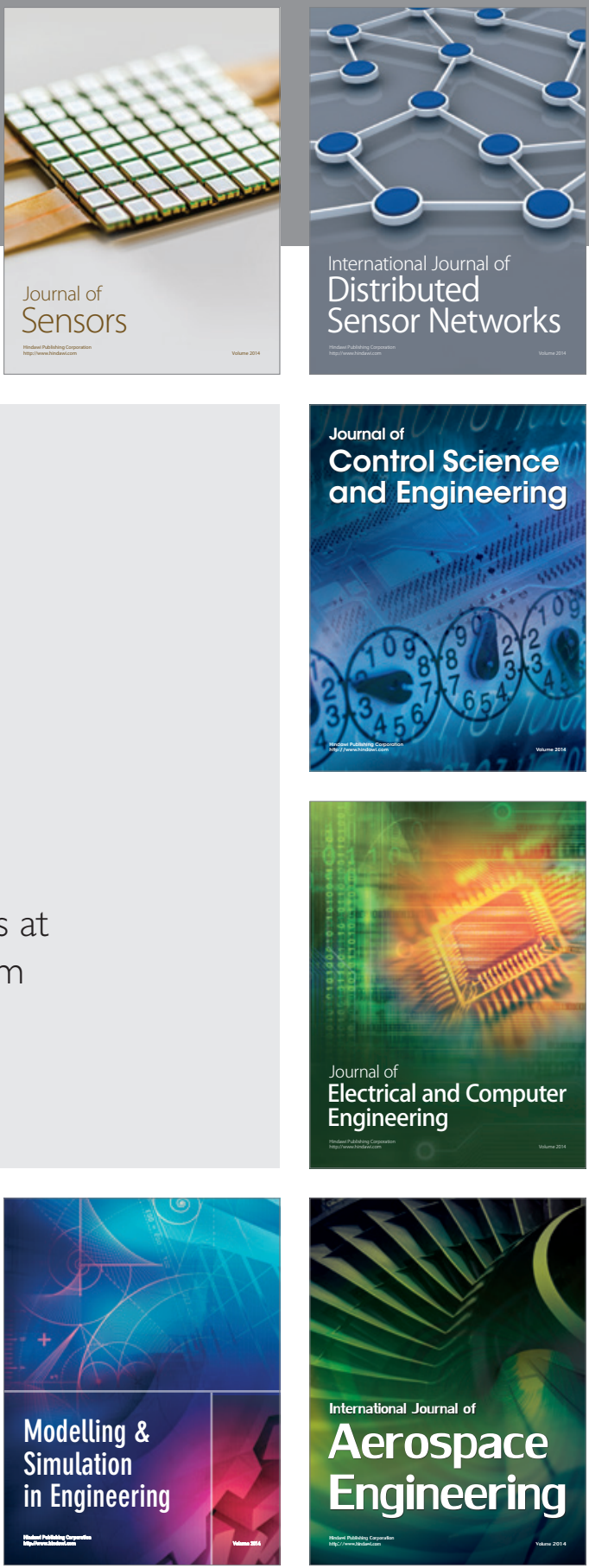

Journal of

Control Science

and Engineering
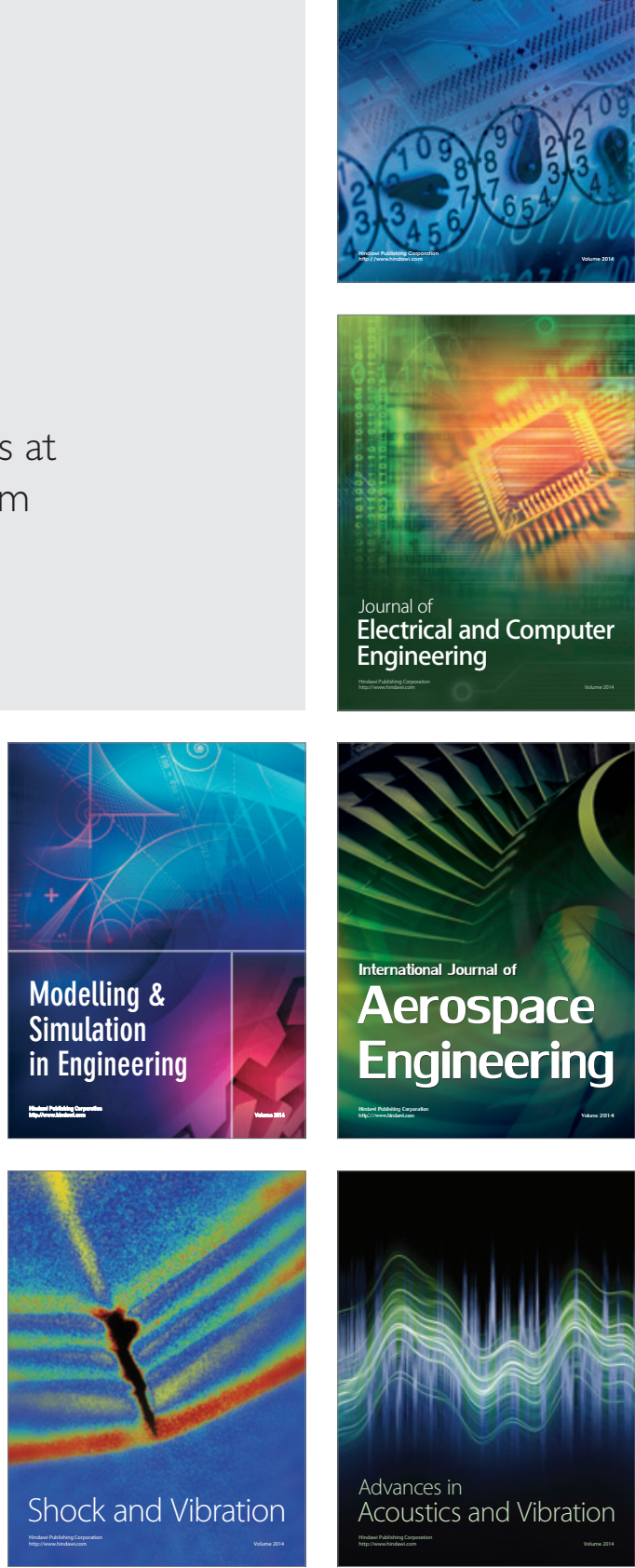